
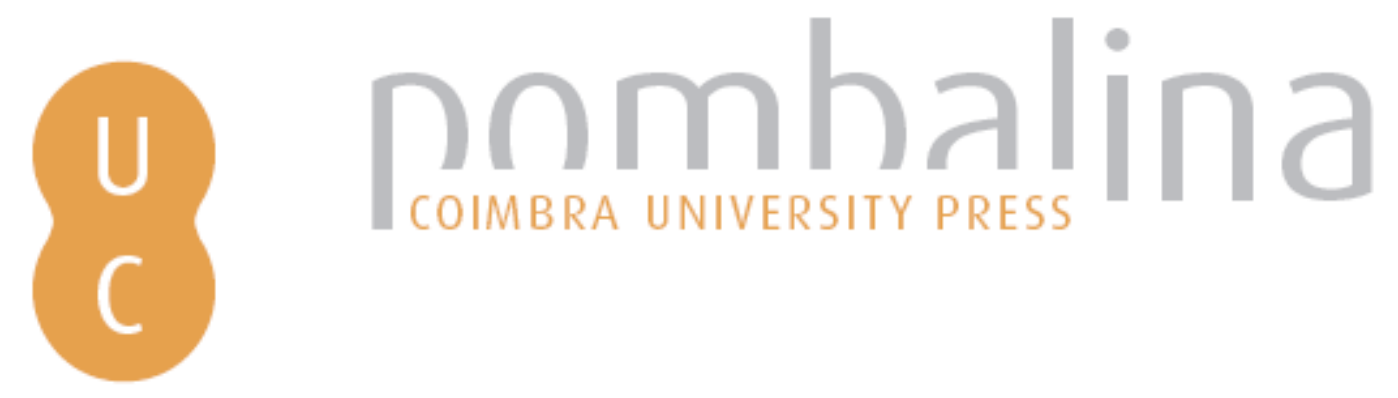

\title{
Salomão parodiado: elementos judaicos na paisagem pompeiana
}
Autor(es):
Rodrigues, Nuno Simões
Publicado por: $\begin{aligned} & \text { Associação Portuguesa de Estudos Clássicos; Imprensa da } \\ & \text { Universidade de Coimbra }\end{aligned}$

URL

persistente:

URI:http://hdl.handle.net/10316.2/31779

DOI:

DOI:http://dx.doi.org/10.14195/978-989-721-069-3_23

Accessed : $\quad$ 26-Apr-2023 14:33:19

A navegação consulta e descarregamento dos títulos inseridos nas Bibliotecas Digitais UC Digitalis, UC Pombalina e UC Impactum, pressupõem a aceitação plena e sem reservas dos Termos e Condições de Uso destas Bibliotecas Digitais, disponíveis em https://digitalis.uc.pt/pt-pt/termos.

Conforme exposto nos referidos Termos e Condições de Uso, o descarregamento de títulos de acesso restrito requer uma licença válida de autorização devendo o utilizador aceder ao(s) documento(s) a partir de um endereço de IP da instituição detentora da supramencionada licença.

Ao utilizador é apenas permitido o descarregamento para uso pessoal, pelo que o emprego do(s) título(s) descarregado(s) para outro fim, designadamente comercial, carece de autorização do respetivo autor ou editor da obra.

Na medida em que todas as obras da UC Digitalis se encontram protegidas pelo Código do Direito de Autor e Direitos Conexos e demais legislação aplicável, toda a cópia, parcial ou total, deste documento, nos casos em que é legalmente admitida, deverá conter ou fazer-se acompanhar por este aviso.

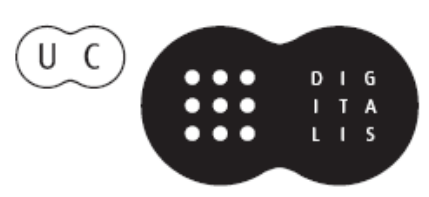




\section{Espaços e Paisagens}

\section{Antiguidade Clássica e Heranças Contemporâneas}

Vol. I Línguas e Literaturas. Grécia e Roma

Francisco de Oliveira, Cláudia Teixeira, Paula Barata Dias (coords.)

IMPRENSA DA UNIVERSIDADE DE COIMBRA 


\title{
SALOMÃO PARODIADO: ELEMENTOS JUDAICOS NA PAISAGEM POMPEIANA
}

\author{
Nuno Simões Rodrigues \\ Universidade de Lisboa \\ nonnius@fl.ul.pt
}

\begin{abstract}
From Pompeii, from the so-called House of the Doctor, comes three frescoes, dated from the $1^{\text {st }}$ century, containing scenes starred by Pigmees. The paintings show: a fight between the little creatures and animals from the Nile; a banquet where some of the invited are entertained with sexual intercourse; and a judgement, where a very young child is upon an altar and woman cries to the judge. There have been several interpretations for this triptych, defending the main one the Alexandrian origin of its subjects. With some other researches before, we agree that the last panel depicts the biblical theme of «The Judgement of Solomon», but we also propose that one must read the three panels as being part of a decorative program, which pretends to show ethnic stereotypes of some of the Roman subdued people, like the Egyptians, the Greeks and the Jews.
\end{abstract}

Keywords: Jews $1^{\text {st }}$ century, Pompeii, Roman painting, Rome $1^{\text {st }}$ century.

Palavras-chave: Judeus séc. I, pintura romana, Pompeios, Roma séc. I.

Em Pompeios, num peristilo da chamada Casa do Médico ${ }^{1}$, havia três frescos com cenas protagonizadas por pequenas criaturas disformes, identificadas como Pigmeus. Esta série de frescos foi descoberta por António Sogliano, em 1882, que os transferiu para o Museu Arqueológico de Nápoles, onde se encontram ainda depositados. As pinturas em causa têm sido datadas do tempo de Augusto 2 .

Um dos frescos representa as pequenas criaturas, travando um combate contra animais selvagens: crocodilos, de aspecto dinossáurico, íbis e um hipopótamo, que engole, ou regurgita, uma delas. Vêem-se embarcações, no

${ }^{1}$ Casa 6, 6, 8. Ver J.R. Clarke (2006), «Three Uses of the Pygmy and the Aethiops at Pompeii: Decorating, "Othering”, and Warding off Demons» in L. Bricault, M.J. Versluys and P.G.P. Meyboom (eds.), Nile into Tiber: Egypt in the Roman World. Leiden, 163; R.A. Tybout (2003), "Dwarfs in discourse: the functions of Nilotic scenes and other Roman Aegyptiaca», JRA 16 505-515.

${ }^{2}$ J.R. Clarke, op. cit., 156. O tema dos Pigmeus, porém, aparecia já em Homero (Il. 3, 6), em Heródoto $(2,32 ; 3,37)$ e na arte grega do século VI a.C., designadamente na cerâmica. 
canto superior direito, enquanto, ao centro, um complexo arquitectónico, sugerindo uma ilha, domina toda a cena (fig. 1).

Um segundo painel mostra um simpósio em que alguns pigmeus se entregam a devaneios sexuais, pouco íntimos, porém. Uma hetera coroada protagoniza o momento de sexo explícito. Um músico acompanha o banquete, enquanto duas personagens parecem filosofar. Do lado esquerdo, repete-se a imagem de um hipopótamo que engole/regurgita um pigmeu, enquanto outro tenta arrancar o companheiro às mandíbulas do animal. $\mathrm{O}$ íbis está igualmente presente (fig. 2).

O terceiro fresco, por fim, apresenta uma cena algo mais complexa. Tudo se passa num pretório, em que três soldados se mantêm perante um juiz/ rei. Dois desses soldados usam uma túnica branca com armadura e capacete, de tipo romano. Um destes segura numa das mãos uma espada, que ergue sobre uma criança, deitada num altar. $O$ terceiro soldado veste uma túnica vermelha e posa como se fosse um grande general ou até mesmo um deus. Três outras figuras, sobre um estrado, ouvem atentamente uma mulher, que se ajoelha perante elas. Das três, evidencia-se a personagem central, ao segurar uma lança como se fosse um báculo, denunciando o seu protagonismo em toda a representação. Junto ao altar, uma segunda mulher acompanha o acto do soldado. A tudo, assistem vários soldados, de pé e atrás dos juízes, e ainda outros homens, dos quais se destaca um que enverga uma toga branca de tipo senatorial. O burlesco, conseguido através da morfologia disforme das personagens de cabeças desmesuradas e tronco e membros demasiado curtos, domina a cena (fig. 3).

Este último painel tem sido alternadamente interpretado pelos investigadores ora como uma representação de uma cena do primeiro livro dos Reis (1Rs 3,16-28), popularmente conhecida como a «Sentença de Salomão», ora como a de um rei egípcio da XXIVa dinastia (sec. VIII a.C.), chamado Bakenranef e conhecido entre os Gregos como Bócoris. Este surge nos textos greco-latinos como uma espécie de legislador e sábio matricial da cultura egípcia $^{3}$. Acreditamos, contudo, estar perante o primeiro caso. Eis os nossos argumentos.

Em primeiro lugar, há que ter em conta o contexto judaico de Pompeios e da região envolvente da cidade. Algumas inscrições revelaram nomes como Jesus, Marta e Maria ${ }^{4}$. Outra antroponímia, ainda que não explicitamente judaica, sugere uma proximidade a essa cultura, sendo, todavia, de origem indubitavelmente oriental: M.Valerius Abinnericus, A. Coss(ius) Liban(us), Libanis ou ainda o possível Felix(?) Youdaikou ${ }^{5}$. A existência de uma inscrição que refere

${ }^{3}$ Aparentando, porém, ser igualmente uma síntese da imagem popularizada de Salomão de Israel. Ver Man. Hist. 64-65; Ael. NA 12, 3; D.S. 1, 65-79; Tac. Hist. 5, 3.

${ }^{4}$ Sobre estes nomes, ver A. Varone (1979), Presenze giudaiche e cristiane a Pompei, Napoli, 11-13. Sobre «Maria», não está excluída a hipótese de se tratar do feminino de Marius.

${ }^{5}$ CIL IV, 1943; 1507; 3763; 4287; 5244; 5630; 7866; 8010; 8866; 9757. A problemática em torno destes nomes pode ser lida em A. Varone, op. cit., 11-13. Aqui se contesta, por exemplo, que Felix Ioudaikos seja um antropónimo, sugerindo-se, em alternativa, que se trata de uma mera 
a expressão princeps libertinorum levou alguns autores a sugerir a existência, em Pompeios, de uma sinagoga semelhante à que se menciona no livro dos Actos dos Apóstolos e que é identificada como a «Sinagoga dos Libertos». Mas esta não é uma conclusão linear nem pacífica, não estando fora de questão que se trate tão-somente de uma associação ligada aos liberti da cidade campanense. Outros dados, contudo, confirmam a existência de judeus em Pompeios, como a nota de Josefo acerca de Agripa, o filho de Félix e Drusila, que terá perecido naquela cidade campanense, juntamente com a mulher, aquando da erupção do Vesúvio, no tempo de Tito ${ }^{7}$. Há ainda informações que permitem perceber a vitalidade da comunidade judaica que ali residia. A mais emblemática é talvez o graffito que menciona dramaticamente «Sodoma e Gomorra» (fig. 4) ${ }^{8}$. Foi já sugerida a autoria cristã ou judaica do mesmo, consistindo talvez numa imprecação feita à cidade, derivada eventualmente da liberdade de costumes que por ali grassava, na perspectiva judaico-cristã; ou num desabafo feito na sequência do terramoto que atingiu a cidade no ano 62 d.C.; ou talvez ainda no âmbito da própria erupção que arrasou Pompeios, e cidades vizinhas, em Agosto de 79 d.C. Apesar de o ductus dos caracteres ter sido datado de uma fase mais antiga, é particularmente atraente, e igualmente perturbador, pensar na possibilidade de que alguém poderá ter traçado tais palavras na parede, no momento em que o enxofre caía sobre a cidade, numa dramática alusão ao fim das duas cidades bíblicas. Seja como for, o autor de tal inscrição conhecia sem dúvida a história narrada no livro do Génesis, pois de outro modo não se encontraria sentido na referência ${ }^{9}$. É ainda a forma GENESIS que se lê em outras duas inscrições, sugerindo igualmente uma forma onomástica judaica ou simplesmente oriental, apesar da origem grega do termo.

Além do mais, podemos levar ainda em conta a ligação da segunda mulher de Nero, Popeia Sabina, à cidade de Pompeios, onde mantinha uma uilla sumptuosa, e simultaneamente a proximidade que a imperatriz tinha com a comunidade de judeus de Roma e com a própria fé judaica. As relações e os contactos que esta dama imperial manteve com o actor judeu de nome Alituro e com o próprio Flávio Josefo são disso evidência ${ }^{10}$. De igual modo, não será

inscrição numa ânfora vinária, identificando o vinho aí guardado.

${ }^{6}$ Act 6,9. Ver J.-B. Frey (1933), «Les Juifs à Pompéi», RBi 42, 370-372; M. Della Corte (1949/1950), «Fabius Eupor princeps libertinorum. Elementi giudaici in Pompei», Atti Acc. Pontaniana 3, 347-353; E. Miranda (1979), «Due iscrizioni greco-giudaiche della Campania», $R A C$ 55, 337-341; A. Varone, op. cit., 14-15; e o nosso estudo (2007), Iudaei in Vrbe. Os Judeus em Roma de Pompeio aos Flávios. Lisboa. Há ainda evidência da existência de comunidades judaicas em várias localidades da Campânia, designadamente em Putéolos, Josefo, Antiguidades Judaicas 17, 330; CIL X, 1893; 1931; 2258; 3303; C. Giordano, I. Kahn (1979), Gli Ebrei a Pompei. Napoli, 19-40; A. Varone (1979), «Giudei e cristiani nell'area vesuviana» in Pompei 79. XIX centenario, sup. Antiqua 15, 131-146.

${ }^{7}$ Josefo, Antiguidades Judaicas 20, 144.

${ }^{8}$ CIL IV, 4976.

${ }^{9}$ Gn 13,$13 ; 19,24-25$.

${ }^{10}$ Ver nosso estudo, op.cit., 636-654 e bibliografia aí citada. E ainda CIL IV, 259; 1499; $1545 ; 6682$. 
inverosímil que a própria Berenice, uma princesa judia da casa real da Judeia, tenha passado algum tempo naquela cidade ${ }^{11}$. E podemos citar ainda a inscrição encontrada em Marano, perto de Pompeios, que refere uma cativa de nome Cláudia Ester, originária de Jerusalém, e que poderá ter sido mulher de Tibério Cláudio Másculo, liberto do imperador ${ }^{12}$. Estes são dados suplementares que nos permitem acrescentar algumas reflexões mais acerca da existência de um contexto judaico pertinente na cidade de Pompeios no século I d.C. De referir ainda que há vestígios judaicos em Putéolos, Nola, Bacoli, Marano, Cápua, Herculano, Estábias e Nápoles ${ }^{13}$.

Em segundo lugar, há a necessidade de perceber qual foi o programa decorativo que presidiu à organização dos painéis na sala da Casa do Médico. $\mathrm{Na}$ verdade somos herdeiros de um pensamento aristotélico, que busca sempre um sentido e uma ordem na organização do real. Talvez o autor do programa decorativo não estivesse necessariamente preocupado em garantir um sentido na escolha dos temas decorativos do aposento, mas o facto é que esse mesmo autor seria um dos mais prováveis herdeiros desse aristotelismo, pelo que o mais provável é que tenha efectivamente havido uma harmonia e um sentido que acabou por presidir à escolha dos temas ali representados.

Os autores que se têm dedicado a esta questão são unânimes em aceitar a ideia de que o recurso à figura do Pigmeu para protagonista do complexo pictórico (sendo ainda de referir que este não é caso único em Pompeios) deverá corresponder a uma espécie de código em que o «disforme» corresponde ao Outro não romano, diferente, como sempre, do Eu diferencial ${ }^{14}$. Note-se que, ao pigmeu, se associam com frequência o anão e o etíope, entendidos amiúde e simultaneamente como paradigmas da diferença e como imagem do Egipto ${ }^{15}$.

${ }^{11}$ Ver nosso estudo, op. cit., 781-798.

12 Cil X, i 97i: [CL] AVDia Aster/ [H]IERosolymitana/ [CA]PTiva CVRAm egit/ [Ti] ClaVDIVS AVG. LIBERTVS/ [MAS] CVLVS ROGO VOS FAC./ [PRAE]TER LEGEM NE QVIS/ [MI] HI TITVLVM DEICIAT CV/ [RA]M Agatis viXit AnNis/ XXV. «(Aqui jaz) Cláudia Ester, natural de Jerusalém, cativa. Tibério Cláudio Másculo, liberto de Augusto, tomou a seu cuidado este monumento. Peço-vos (a vós que passais) que façais com que ninguém, contra a lei, me destrua esta inscrição e que a tomeis ao vosso cuidado. Viveu vinte e cinco anos.»

${ }^{13}$ C. Giordano, I. Kahn, op. cit., 19-40. Outros dados, porém, parecem-nos menos evidentemente judaicos. Referimo-nos à estatueta que representa um vendedor e cuja principal característica é o pénis desmesurado e que, por esse motivo, tem sido identificado como um judeu. Sobre esta peça, também depositada no Museu de Nápoles, refira-se que a identificação como judeu tem sido feita apenas com base na fisionomia, designadamente a barba e o cabelo, e por analogia com Mart. 1, 42. Na verdade, a representação do órgão sexual masculino em estado flácido, ainda que de tamanho desmesurado, apoia essa leitura, uma vez que os Romanos associavam a prática da circuncisão ao tamanho alargado do pénis. Mas a referida peça não apresenta o pénis circuncidado, pelo que baseado apenas no tamanho nos parece pouco sustentável para afirmar tratar-se de um judeu. Ver nosso estudo, op. cit., 647-650.

${ }^{14}$ J.R. Clarke, op. cit., 155-156; F. Hartog (1980), Le miroir d'Hérodote. Paris, passim.

${ }^{15}$ J.R. Clarke, op. cit., 160. 
Essa imagem de alteridade pretenderia evidenciar a superioridade da cultura referencial por contraposição à do Outro ${ }^{16}$.

Apesar de se ter já sugerido o episódio de Jonas, numa versão de paródia, como leitura para o primeiro painel, essa tese não tem tido grandes adeptos, sendo considerada de débil sustentabilidade. Por outro lado, é verosímil que a escolha deste tema se tenha baseado num passo de Plínio, no qual se lê uma descrição nilótica aproximada do que se vê nesta representação ${ }^{17}$. De facto, a fauna ali presente é característica do ecossistema definido pelo rio Nilo. Este fresco representará, portanto, os Egípcios numa cena do seu quotidiano ${ }^{18}$. Seguindo esta linha de raciocínio, há também unanimidade em aceitar essa cena como intencionalmente concebida, com um sentido de desprezo étnico pelos Egípcios no seu ambiente natural. Refira-se, aliás, que os temas egipcianizantes parecem ter sido frequentes neste contexto, demonstrando uma ambígua relação de atracção/desprezo por essa cultura e povo. Além disso, este tipo de representação sugere igualmente uma provável influência alexandrina, em que as imagens positivas deram lugar à crítica satírica que tem como objectivo inferiorizar o Outro. Tenha-se ainda em atenção que, na Antiguidade Clássica, Alexandria estava às portas de Pompeios, uma vez que a viagem feita por via marítima ligava as duas cidades de uma forma quase directa.

Quanto ao segundo painel, poucos se têm demorado na sua leitura, reduzindo-o à representação de uma outra cena nilótica e acentuando sobretudo o carácter algo pornográfico do mesmo, quer por um hipotético acanhamento quer por excessivo pudor intelectual. O centro da acção, todavia, é o banquete propriamente dito, em torno do qual tudo acontece. Ora, o tema simposíaco está principalmente associado ao universo helénico. Entre os Gregos, o simpósio era de tal modo importante que se tornou tema iconográfico e literário de excelência, como testemunham Platão, Xenofonte, Plutarco e Ateneu, por exemplo. Sabemos também que, associado ao banquete, estava algum desenfreio, que incluía actividade sexual ${ }^{19}$. A representação do músico, da hetera coroada com flores e as personagens que parecem filosofar são, quanto a nós, argumentos suplementares para considerarmos estar perante a representação satírica de um banquete grego e, consequentemente, dos seus principais cultivadores: os Gregos. É verdade que a cena é igualmente assombrada por um hipopótamo que devora um pigmeu e por um íbis, evocando o universo do Nilo. Mas cremos que isso não invalida a representação enquanto sátira dos Gregos. Apenas a coloca igualmente em ambiente nilótico, de acordo com a moda na época. Além disso, sendo uma cidade egípcia, Alexandria era sobretudo um centro cultural grego ${ }^{20}$.

\footnotetext{
${ }^{16}$ J.R. Clarke, op. cit., passim.

${ }^{17}$ Plínio 8, 92. É também Plínio que se refere aos Pigmeus, radicando-os no Egipto. Mas, como anotámos, também já Heródoto o fazia $(2,32 ; 3,37)$.

${ }^{18}$ W.B. McDaniel (1932), «A Fresco picturing Pygmies», AJA 36/3 260-271.

${ }^{19}$ M.T. Schiappa de Azevedo (1991), «Introdução» in Platão, O Banquete. Lisboa 11.

${ }^{20}$ De igual modo convém referir que em Alexandria havia uma hostilidade particular contra o Judaísmo ver nosso estudo, op. cit., 45-47.
} 
Assim, se o primeiro painel representa os Egípcios e o segundo os Gregos, é então plausível que o terceiro represente uma terceira etnia e cultura, igualmente significativa no Mediterrâneo do século I a.C.-I d.C.: a dos Judeus. Estes surgem igualmente através da expressão iconográfica, em forma de paródia a um passo literário, como acontece com os casos anteriores (em parte a Plínio, no primeiro caso, e a sátira ao tema do banquete, no segundo): a «Sentença de Salomão» ${ }^{21}$. Este episódio teria sido transmitido por via oral (o tema seria facilmente conhecido em Alexandria) ou através da leitura da tradução dos LXX. Neste sentido, não é de desconsiderar a hipótese de o artista, ou o seu mentor, ter estado bem familiarizado com o ambiente alexandrino. Por outro lado, que as elites romanas conheciam passos e episódios bíblicos é um facto comprovado por vários estudos ${ }^{22}$. Esta seria assim apenas mais uma representação dessa natureza.

Em síntese, consideramos estar na presença de uma harmonia estética, de um programa decorativo, que assenta na representação do Outro. Estaremos assim perante uma paisagem preenchida com representações de alteridade, numa evocação que se faz através de uma imagética satírica e paródica, que denuncia igualmente a vivência de uma cidade cosmopolita e ligada pelo mar ao mundo mediterrâneo, atraindo gentes e culturas. A presença de gregos em Pompeios está atestada, bem como a de egípcios e judeus. A mesma faziase notar particularmente através da expressão religiosa, como eram os cultos mistéricos de origem helénica, a devoção a Ísis, particularmente importante em Pompeios como demonstra o templo aí dedicado a essa deusa, ou as práticas relacionadas com os diversos tabus comportamentais judaicos. Estas eram não só as culturas estrangeiras mais presentes nas principais cidades romanas, como também as eventualmente mais concorrenciais: a Grécia, o Egipto e a Judeia-Palestina eram gigantes culturais, que Roma tinha necessariamente de enfrentar e com que lidar. A partir do século I a.C., em especial, a reacção dos Romanos a tais estrangeirismos, em particular aos orientalismos, não foi a mais simpática, como aliás lemos em autores como Petrónio ou Juvenal ${ }^{23}$. Até mesmo a hostilidade para com a cultura grega não era inédita em ambiente romano $^{24}$. O tipo de iconografia aqui apresentado virá, portanto, nessa linha. Como tal, o objectivo de tais representações seria, sobretudo, troçar e fazer rir, constituindo eventualmente até um instrumento de função apotropaica, como, aliás, foi já demonstrado ${ }^{25}$.

${ }^{21}$ Dado o seu carácter mais concreto, por ser baseado num texto concreto pré-existente, é mais correcto falar-se de paródia no caso da «Sentença de Salomão».

${ }^{22}$ Ver e.g. G. Rinaldi (1989), Biblia Gentium. Primo contributo per un indice delle citazioni, dei riferimenti e delle allusioni alla Bibbia negli autori pagani, greci e latini, di età imperiale. Roma, passim.

${ }^{23}$ Ver nosso estudo, op. cit., 738-751, 821-825.

${ }^{24}$ Recordamos a realidade do tempo de Catão, por exemplo. O filo-helenismo de Nero sugere também a existência de uma posição anti-helénica em Roma.

${ }^{25}$ J.R. Clarke, op. cit., 156. A tese segundo a qual estamos perante três cenas nilóticas, e em que a terceira se reporta à figura de Bócoris em vez da de Salomão, não é totalmente desprovida de sentido. Os elementos egípcios são comuns aos três painéis, da figura do pigmeu à fauna ali 


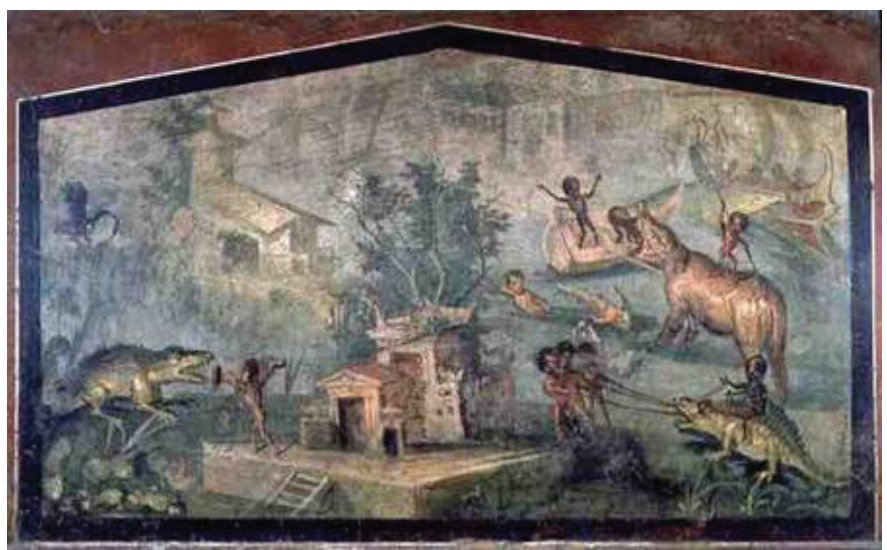

Fig. 1 - Cena nilótica com luta de pigmeus contra animais

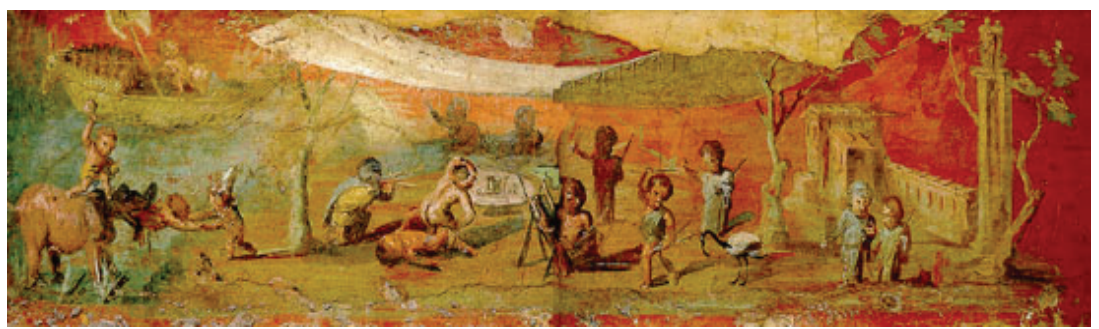

Fig. 2 - Cena de banquete

presente. Mas a cena do banquete, com a presença da hetera coroada leva-nos a preferir a hipótese que aqui propusemos. Por outro lado, a cena que se centra na criança que estás prestes a ser repartida por duas mulheres fortifica a hipótese salomónica, também. Não nos parece viável a hipótese de o primeiro painel representar os monstros citados no livro de Job, Beemot (o hipopótamo) e Leviatan (o crocodilo), visto que, aparentemente, essa ideia não confere coerência ao conjunto de painéis. Não deixa de ser curiosa, porém, a coincidência entre as criaturas primordiais ali descritas e a representação iconográfica. Sobre essas criaturas, ver Jb 40, 15-24; 41; e o apócrifo 1Enoc 60, 7-8. 


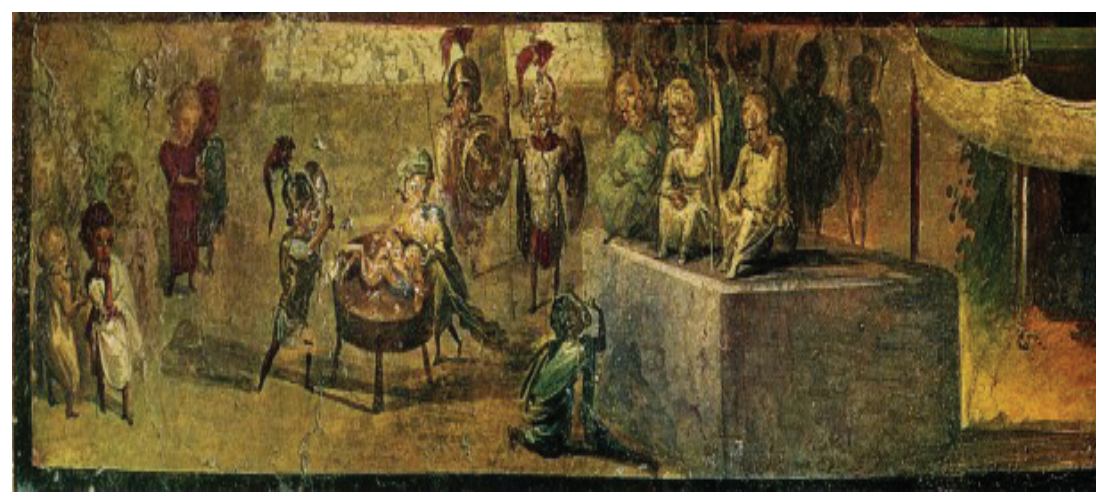

Fig. 3 - Cena representando julgamento

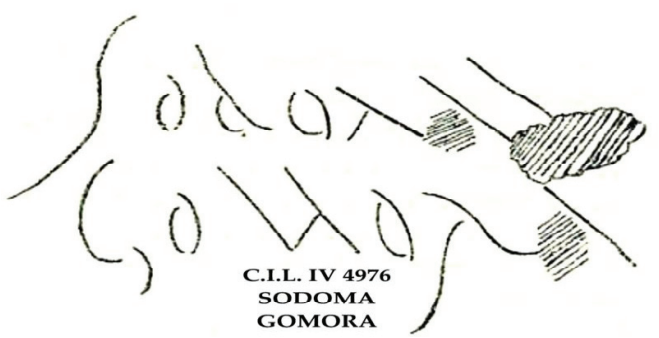

Fig. 4 - Graffito indicando Sodoma e Gomorra (CIL IV, 4976). 